Association for Information Systems

AIS Electronic Library (AISeL)

Wirtschaftsinformatik Proceedings 2005

Wirtschaftsinformatik

February 2005

\title{
Drivers and Impediments of Consumer Online Information Search: Self-controlled versus Agent- assisted Search
}

Sarah Spiekermann

Humboldt-Universität zu Berlin

Dirk Temme

Humboldt-Universität zu Berlin

Martin Strobel

Maastricht University

Follow this and additional works at: http://aisel.aisnet.org/wi2005

\section{Recommended Citation}

Spiekermann, Sarah; Temme, Dirk; and Strobel, Martin, "Drivers and Impediments of Consumer Online Information Search: Selfcontrolled versus Agent-assisted Search" (2005). Wirtschaftsinformatik Proceedings 2005. 87.

http://aisel.aisnet.org/wi2005/87

This material is brought to you by the Wirtschaftsinformatik at AIS Electronic Library (AISeL). It has been accepted for inclusion in Wirtschaftsinformatik Proceedings 2005 by an authorized administrator of AIS Electronic Library (AISeL). For more information, please contact elibrary@aisnet.org. 
In: Ferstl, Otto K, u.a. (Hg) 2005. Wirtschaftsinformatik 2005: eEconomy, eGovernment, eSociety; 7. Internationale Tagung Wirtschaftsinformatik 2005. Heidelberg: Physica-Verlag

ISBN: 3-7908-1574-8

(C) Physica-Verlag Heidelberg 2005 


\title{
Drivers and Impediments of Consumer Online Information Search: Self-controlled versus Agent-assisted Search
}

\author{
Sarah Spiekermann, Dirk Temme \\ Humboldt-Universität zu Berlin
}

Martin Strobel

Maastricht University

Abstract: This research investigates drivers of consumer's online search activity. Traditional constructs relevant in offline information search (including perceived product risk, purchase involvement and product knowledge) are tested for an online environment on the basis of a structural equation model. In addition, new constructs impacting online search, namely privacy concerns and flow, are analysed. A major contribution of this research is the explicit distinction of consumers' preference for agent-assisted search versus self-controlled search forms. The analysis is based on 116 subjects that were observed in their search behaviour during a 'real-world' shopping trip for cameras.

Keywords: online shopping, agents, information search, decision-support

\section{Introduction}

Since we can observe an increasing use of the WWW as a source of product purchase information a long row of research on consumer product choice processes is being questioned. This is, because the new electronic medium promises to considerably reduce traditional search cost relevant in offline markets [Alba ${ }^{+}$97, Bak97], offers an exciting amount of new product information sources and efficiently supports the search process through agent technology and other personalization features [ $\operatorname{Kar}^{+} 03$, HäTr00]. Within a few years, the Internet has evolved as a major source of product information retrieval. In many areas it now serves $10-20 \%$ of customers to prepare their purchases [Eco04].

When the market dynamics of the Internet economy are studied, scholars have a tendency to assume the widespread deployment and use of highly performing search engines or personal agent technologies. Based on the fascinating idea that there is a highly efficient and reliable technology at work that has all relevant in- 
formation at hand, they have started to integrate a 'minimal search cost perspective' in their models and investigated, for example, the consequences for pricing [Bro00] and market dynamics [Alba ${ }^{+}$97]. Little research emphasis has been attributed, however, to the fact that consumers may not exclusively want to base their purchase decision on agent recommendations. For example, consumers may not trust the technology to the necessary end and may therefore wish to complement agent suggestions with a personally conducted and more controlled search activity. Urban et al. (1999), for example, who tested consumers satisfaction with a 'trust-based advisor' found some evidence that subjects with different predispositions in the purchase process (e.g. different levels of product knowledge) react differently to the support technology. It is therefore important to ask to what extent and why consumers recur to agent recommendations for their purchase decisions, or, in contrast, prefer information search that they control more.

The study presented hereafter proposes and tests a comprehensive model of Internet based information search. It explicitly respects the existence of two different types of search conducted online: interaction with an electronic decision-support system on one side and personally controlled, detailed inspection of product descriptions on the other.

Following this introduction, section 2 summarizes a structural equation model on online information search. Section 3 describes the methodology we employed to test our model. Section 4 describes the way of measurement. Eventually, Section 5 reports on the results obtained commenting on model fit as well as the acceptance or denial of individual hypotheses tested. Here, we also expand on the relative importance of agent supported search versus detailed product inspection. Section 6 concludes with a summary of major findings.

\section{Proposed Model of Online Information Search}

We propose a model of drivers and impediments of online information search. At its centre is the amount of search activity displayed by subjects. This search activity is hypothesised to be dependent on a number of variables: purchase involvement, product experience, product class knowledge, perceived risk, stage in the buying process, privacy concerns, cost and benefits of search as well as the achievement of a flow status. Figure 1 gives an overview of the hypothesised constructs and their relationships. 


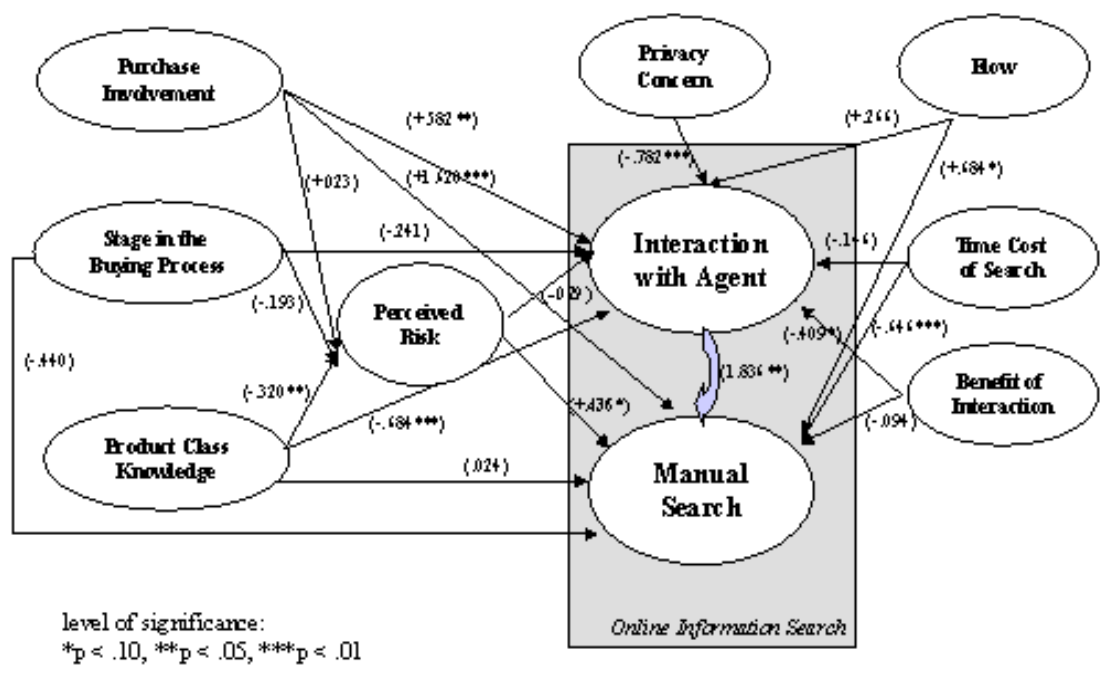

Figure 1: Proposed structural equation model for online information search and results

There are two prominent ways in which product information is sought online: One is to obtain information by consulting detailed product descriptions. Here, pure site navigation, the use of product fact sheets, comparison matrices and photographs is a common means employed in online environments. We refer to this as manual search. Another way to search for products online is the use of interactive decision support systems that allow for more efficient attribute sorting of products and comparative shopping (e.g. MySimon.com). For modelling purposes we distinguish between these two different types of online information search. They are the dependent variables in the model investigated.

Search activity prior to purchase has repeatedly been shown influenced by perceived risk. Perceived product risk denotes a consumer's assessment of the consequences of making a purchase mistake, as well as of the probability of such a mistake occurring [Cun67]. As a result of this initial risk assessment consumers engage in information search in order to reduce the perceived risk to an acceptable level [DoSt94, SuTa98].

In our model we postulate that higher levels of perceived risk lead participants to use both means of search in a relatively intensive manner. 
H1: The more product risk a consumer perceives prior to the purchase of a camera, the more he or she will interact with an electronic advisor agent.

H2: The more product risk a consumer perceives prior to the purchase of a camera, the more will he or she consult detailed product information.

A recognized construct in structural equation models of information search [PuSt83, SrRa91] (and theoretical reflections thereon) [ $\left.\mathrm{Moo}^{+} 97\right]$ is the cost benefit judgement consumers make. Cost of search in these studies represent the accumulation of physical and cognitive effort as well as monetary expenditures necessary to find the right product. Benefits of search have been described as satisfaction with the product chosen or cost savings realized through the search activity [PuSt83].

In an online context, perceived cost and benefits of search will probably continue to trigger search effort. Yet, especially the cost side may be of a different nature online than offline. Even though many traditional search cost variables may be comparatively less important in online environments, two traditional information search cost factors, namely information processing time and ease of access to information, remain important in online environments [HoLo99, LyAr00]. As a result, time cost has been included in our model applying it to the interaction process with an agent. Consumers may weigh the number of specifications they provide to a decision support tool and potentially skip interactive search categories in order to minimize time investment. Two hypotheses have been derived:

H3: The more time cost a consumer perceives while searching for product information, the less will he or she interact with an electronic sales agent.

H4: The more time cost a consumer perceives while searching for product information, the less they will consult detailed product information.

As in offline environments, the benefits of search reside in the identification of an appropriate product. Therefore, assuming that the agent is valued, consumers should feel that interacting with an agent helps them identifying the right product and consequently invest into a relatively extensive dialogue (at least in a highinvolvement context). If agent interaction is beneficial, they will probably invest less effort into manual search. Based on this reasoning we hypothesize a competitive effect for the two search forms:

H5: The more benefits a consumer perceives from interacting with an agent, the more they will interact with it.

H6: The more benefits a consumer perceives from interacting with an agent, the less will he or she search manually. 
Another construct in offline information search is product knowledge [SrRa91, BeSm87, PuSt83]. Yet, what consumers actually know about a product category (objective knowledge) and what they think they know (subjective knowledge) is often differing and may have diverging effects on search [Bru85]. Subjective product knowledge investigated here was expected to limit search by allowing responses to become routine or by allowing relevant information to be easier separated from the irrelevant. Furthermore, we argue along existing marketing literature that those consumers who have more knowledge on a product also perceive less purchase risk [SrRa91, SuTa98].

H7: The more knowledge a person states to have about a product category, the less will he or she interact with an electronic advisor agent.

H8: The more knowledge a person states to have about a product category, the more will he or she consult detailed product information.

H9: The more knowledge a person states to have about a product category, the less risk will he or she perceive when confronted with a buying situation in the respective category in an online context.

A concept that has gained considerable recognition in the study of information search is the level of involvement a consumer has with the purchase situation [BeMs87, PuSte83]. Purchase involvement can be described as "a person's perceived relevance of the object based on inherent needs, values and interests" [Zai85, p.341]. Involvement is seen as a motivational factor in consumer choice behaviour and is attributed mainly to three causes [Dei89]: personal predisposition (i.e. subjective needs or goals), situational factors (e.g. time pressure) or stimulusdependent factors (e.g. influence of product or communication). While situational involvement has been integrated in the model as a separate construct, stimulusdependent involvement has been seized indirectly through the construct of product knowledge and perceived risk. Involvement is expected to play on both, agent interaction and manual search. A number of authors suggested that purchase involvement is also closely related to the consequences element of perceived risk [BeSm87]:

H10: The more involvement a consumer has with a purchase situation, the more will he or she interact with an electronic sales agent.

H11: The more involvement a consumer has with a purchase situation, the more will he or she consult detailed product information.

H12: The more involvement a consumer has with a purchase situation, the more risk will he or she perceive when confronted with a buying situation in an online context.

Some studies have been looking explicitely into online interactivity. For example, based on the theory of exchange developed in marketing literature, Swaminathan et al. (1999) tested the impact of vendor characteristics, transaction security, pri- 
vacy concerns and customer characteristics on the likelihood of electronic exchange. Other studies observed the importance of secure financial transactions for consumers' perceived risk in online transactions. Quite some research attention has been attributed to the impact of privacy concerns on information exchange [Spi $\left.{ }^{+} 01, \mathrm{Swa}^{+} 99\right]$ and to the existence of flow in online navigation [HoNo96, $\left.\mathrm{Nov}^{+} 00\right]$. These two constructs, privacy and flow, have therefore been integrated in our online search model.

Privacy can be sacrificed by both interacting with an agent, or by simply navigating online sites. Web servers usually log every of the users' activity. However, as was outlined above, when consumers interact with advisor agents on a website (which ask for key-words or retrieve personal data through dialogue-based systems), they reveal a particularly large amount of direct personal information. Consumers were therefore expected to be cautious when using the interactive applications leading to the hypothesis:

H13: The more privacy concern a consumer expresses over the revelation of personal data, the less will he or she interact with an electronic sales agent.

Another phenomenon occurring when navigating in online environments is 'flow'. The flow status is a psychological state that has been investigated in the context of intrinsic motivation since the 1960's [CsCs95]. Hoffman and Novak (1996) observed its relevance for online environments and Novak et al. (2000) defined it as a "state occurring during network navigation which is: (1) characterized by a seamless sequence of responses facilitated by machine interaction, (2) intrinsically enjoyable, (3) accompanied by a loss of self-consciousness, and (4) selfreinforcing." Thus, when consumers search for information online, it is possible that they loose perception of time and keep on navigating longer and in more directions than they initially planned to. Seen the creation of flow in online environments, the aim was to control this phenomenon with the following hypotheses:

H14: The more flow a consumer perceives, the more will he or she interact with an electronic sales agent.

H15: The more flow a consumer perceives, the more will he or she consult detailed product information.

Finally, it is intuitive to suggest that online consumers, who used physical retail channels to get an overview of the product category and are thus more advanced in the buying process than their peers, engage in less information search online than those who entered the online search process unprepared. Even though the stage in the buying process and product knowledge are related concepts, they have been distinguished here for modelling purposes. Consumers could have felt knowledgeable about a product category without having gone to a store in advance of the online shopping trip. At the same time, subjects may have gone to a store before shopping online, but still felt little knowledgeable about the product category. Given this, it was hypothesized that: 
H16: The further a consumer is advanced in the buying process; the less will he or she interact with an electronic sales agent.

H17: The further a consumer is advanced in the buying process, the less will he or she consult detailed product information.

H18: The further a consumer is advanced in the buying process, the less risk will he or she perceive when confronted with a buying situation in an online context.

\section{Method}

In November 2000 an experiment was carried out with 151 participants to observe consumer information search behavior during an online shopping trip for a compact camera.

\subsection{Participants, Incentive Scheme and Briefing}

The experiment was advertised at Humboldt University Berlin, Germany. Its goal was described as a test of user interaction with a highly innovative product search engine. The online environment we said would be hosted by the industrial sponsor of the project who did not wish to be named. All navigational data would be transferred to this company. If people chose to buy something in the store they had to spend their own money. The main incentive to participate in the experiment was a $60 \%$ discount offered on the catalogue prices of cameras displayed in the store even though this still implied an expenditure of at least $€ 40$ in case of buying. ${ }^{1}$ $95 \%$ of the resulting participants were students from different university faculties, while the remaining $5 \%$ held different jobs. $55,8 \%$ decided to buy a camera during the experiment.

\subsection{Online Material and Apparatus}

The shopping trip took place in an online store called "MCJC Store" explicitly programmed for the experiment. The main reason for choosing a self-developed experimental store instead of using log-file material from some conventional online retailer was that we wanted to observe online search behavior with a view

Since project finances did not allow us to offer this discount to all buyers, however, the incentive structure was slightly refined such that a lottery after the shopping session decided on one out of 10 participants who would have the right to take the product for the $60 \%$ off. The remaining participants received a small financial compensation. If someone had not bought, but won the lottery, he or she would go out empty. 
to $2^{\text {nd }}$-generation interface-agent systems. For this purpose we needed a highly interactive environment offering users the possibility not only to specify hard product attributes, but also to enroll in an online sales conversation. An animated 3-D shopping agent image licensed from Artificial Life was therefore used to assist the user in product search. 56 purchase related questions were developed that would treat different 'harder' and 'softer' aspects connected to the purchase situation [Ann $\left.{ }^{+} 01\right]$. Shoppers could answer as many questions as they deemed necessary to receive a recommendation. They were briefed that the agent would be able to calculate a reliable Top-10 ranking of the 50 different camera models on the basis of three questions answered.

The navigation opportunities participants encountered in the store were organized in three phases: When participants entered the experimental store they had a space for orientation (phase 1) where they had the possibility to view all products on offer one by one from a list. From there, users proceeded to the search engine where the anthropomorphic 3-D shopping agent Luci introduced herself and her purpose to the user and started a communication or interaction phase. The agent interaction phase relevant in our model (phase 2) was organized in 7 cycles of 7-10 purchase related questions that a user could run through with the agent. The 7 question cycles were displayed to the user on a category survey page leaving him the choice to run through the agent questions in any order he preferred. After viewing a ranking list based on questions answered, customers could then view a more detailed description of each product and enlarge its photograph (phase 3 ). The detailed product description contained a brief marketing text on the respective model displayed, a small photograph and a fact sheet summarizing major product attributes. However, no brand names were displayed in the store on any of the products. The reason for this manipulation was that brand names serve as information chunks for consumers [JaHo81, Wei81]. "Information chunks are information that are particularly relevant for the judgment of products and that are able to substitute or bundle a number of other information" [KrWe99, p.280]. The shopping process could be exited at any time and a purchasing decision could be made after the request for a product information page. Before and after the shopping trip, all participants answered a questionnaire in which model variables were integrated. 


\section{Measures}

\subsection{Measurement of Endogenous Model Constructs}

\subsubsection{Measurement of the Information Search Behaviour}

In the literature on offline information search, search activity has typically been operationalised by the time employed, the number of stores visited, the number of product alternatives inspected, etc. [BeSm87, PuSt83]. For the purpose of the current study, measuring information search levels had to be adjusted to the electronic medium. While the relative amount of time spent searching was kept as one factor representing the search effort, the number of page requests was added as a second measure. Time was recorded for interaction with the electronic agent (phase 2) and for the two product inspection periods (phases $1 \& 3$ ). The time for interaction with the agent has been represented through the total time spent on answering agent questions and going back to the seven-category survey-page. The number of page requests in the context of agent interactivity stands for the intensity of exchange a user sought with the electronic agent. As was described above, the agent asked 56 purchase related questions, each of them representing a separate page. Users could return to this interactive functionality at any time during the shopping process and modify answers initially given. This activity of modifying specifications added to the number of page requests in the interaction cycle as well as the time spent on the functionality. Finally, calls for the Top-10 ranking originating from the agent dialogue or the 7-category survey-page have been added to the number of page requests representing the breadth of agent interaction.

The number of individual product alternatives viewed added to the manual search construct. In addition to this detailed description, users had the possibility to enlarge the photograph of each object in a separate page. The number of photo enlargements has been added as additional page requests to the construct of manual search. Finally, product descriptions were always requested from a page that listed the models available. Together, product model lists, factual descriptions and photo enlargements made up the number of page requests for the dependent manual search construct.

\subsubsection{Measurement of Perceived Product Risk}

Previous work was referred to in order to measure product category risk. As described in literature [Kap $\left.{ }^{+} 74\right]$, perceived risk has been characterized as a multidimensional construct with people differentiating between several negative consequences of a purchase including functional, financial, sociological and psychological risk. For the current model, risk dimensions have been combined into one 
overall index (that has been proposed and tested by academics in earlier studies [PeTa75]). As a result, risk has been captured in the following way:

$$
O P R_{j}=\sum_{i=1}^{n}\left(P L_{i j} \cdot I L_{i j}\right) \quad \begin{aligned}
& O R P_{j}=\text { overall perceived risk for brand } \mathrm{j} \\
& P L_{i j}=\text { probability of loss } \mathrm{i} \text { from the purchase of } \\
& \text { brand } \mathrm{j} \\
& I L_{i j}=\text { importance of loss } \mathrm{i} \text { from purchase of brand } \mathrm{j} \\
& n=\text { risk facets (here } n=4)
\end{aligned}
$$

In the pre-shopping questionnaire, risk perception was measured by employing a 15-point scale for both dimensions, probability and importance of loss. In order to calibrate the way in which different people respond to scales, each individual had to rate not only camera purchases, but also potential dangers and probabilities of loss associated with 'extreme products' in terms of risk, namely toothpaste and used automobiles.

\subsection{Measurement of Exogenous Model Constructs}

In order to measure time cost, earlier studies were considered which have introduced the idea of measuring time cost as opportunity cost. For example, Srinivasan and Ratchford (1991) measured time cost by asking people for their general time constraints and implied that this perception would be a measure for the opportunity cost perceived while searching for product information. In the present study, time cost was therefore grasped similarly by asking participants after shopping whether they had the feeling during search that they would have rather done something else.

The problem in specifying the benefit construct is that, strictly speaking, benefits are not an antecedent, but a result of search. More precisely, perceived benefits of search are the anticipated result of each additional search step performed $\left[\mathrm{Moo}^{+} 97\right.$, Wei79]. Studies that measure the benefits of search should therefore try to capture either expected or ongoing benefits of search. This, however, has turned out to be a challenge. Either studies referred to the post satisfaction with the product bought [SrRa91] or employed very general measures testing for consumers' backward belief in the merits of the search activity. Doing so, self justification may have impacted responses. On the other hand, measuring expected benefits of search prior to the actual search taking place carries the risk to prime subjects' behaviour. The measurement problem was attempted to be circumvented by taking the perceived quality of agent recommendations as an indicator for perceived search benefits. For this purpose participants had to indicate on a 5-point scale after the shopping process how well the agent hit one's needs.

For the measurement of product knowledge we used scales from [MoLe80, SrRa91] asking participants to rate on a 5-point scales how regularly they would 
advice peers in the choice of electronics and to what extent they perceive themselves knowledgeable in the product domain.

Involvement was deducted form asking participants about the importance of a camera purchase that day for a $60 \%$ discount (5-point scales) as well as the urgency of a new camera (4-point scale).

In order to measure privacy concerns, some of the scales developed by Ackerman et al. (1999) were used. Participants were asked ten questions reflecting to what degree they would be ready to reveal certain types of information about themselves on a web site, including identification information (e.g. address or name) and profiling information (e.g. hobbies or income). The arithmetic mean of answers given to these 10 questions provided an index for participants' privacy concerns.

Flow is a construct that is relatively complex to measure. In psychological experiments conducted by Csikszentmihalyi and Csikszentmihalyi (1995), the socalled Experience Sampling Method (ESM) has been employed which involves permanent and unexpected measurement of the current state of consciousness during an activity. As such a constant measurement of flow was not practicable in the shopping experiment, an additive index has been developed that is based on a number of questions capturing the flow experience as defined by Csikszentmihalyi and Csikszentmihalyi (1995) and Novak et al. (2000). The index was calculated by taking the mean of five answers provided on a 9-point scale to questions on the ability and challenge to use the shopping interface, concentration, forgetting oneself and having the feeling of rather doing something else; all contructs derived from [CsCs95].

Finally, the fact that some participants had gone to a physical retail outlet was taken into account in advance of the experiment. There, some had already chosen products of interest for themselves that they now wished to buy for a $60 \%$ discount in our online store. Even though the online store made it difficult for them to rapidly identify their consideration set due to the lack of brand names, these subjects might still have behaved differently to those who were not informed. Subjects were therefore asked in advance of the buying session whether they had informed themselves of the product they wanted to purchase before coming to the lab and also to what degree they had already decided on products (consideration set). The two answers given were then combined to one additive index entitled Stage in the Buying Process. 


\section{Results}

\subsection{Data}

Before model estimation, the data was screened for outliers, which led to an exclusion of 6 from 151 observations. In addition, 29 subjects had missing data, which we originally wanted to impute. However, imputing missing values by using a Maximum-Likelihood approach [LiRu87] implies multivariate normal data. Using PRELIS 2.30 [JöSö96] we tested the assumption that the variables are normally distributed. The multivariate tests [Bol89] after listwise deletion of 29 cases with missing data show that the remaining data is significantly skewed $(\mathrm{z}=5.42, \mathrm{p}$ $=.000)$ whereas multivariate kurtosis represents a borderline case $(\mathrm{z}=2.45, \mathrm{p}=$ .014). An omnibus test on multivariate skewness and kurtosis $\left(\chi^{2}=35.37, \mathrm{p}=\right.$ $.000)$ further indicates that the data is not normally distributed, although deviation from normality seems to be rather modest and in the first place concerns indicators for information search behaviour. As a result, model estimation had to be based on 116 cases.

\subsection{Model Estimation and Fit}

We used a structural equation modelling approach to simultaneously test model constructs and their relations. The model was estimated by the software program Mplus [MuMu98] which uses Maximum-Likelihood (ML) estimation as a standard modelling approach. Yet, since our data is not normally distributed we used the more robust MLM estimation option available in Mplus (this choice has an effect on the estimated standard errors for parameter estimates as well as the Chisquare test statistic, which corresponds to the re-scaled test statistic developed by Satorra and Bentler $(1988,1994))$.

In an initial model estimation thus conducted with MLM four of our latent variable indicators had negative measurement error variances. These so-called "heywood cases" often occur in structural equation modelling under the conditions of a small sample size and few indicators per latent variable [AnGe84, Boom82]. We therefore set a strategy negative error variances to zero, a strategy pursued by earlier studies on information search [PuSt83].

Fit measures for this model were highly satisfactory. The RMSEA of .038 is considerably below the cut-off value of $.05[\mathrm{BrCu} 93, \mathrm{HuBe} 99]$ and both $\mathrm{CFI}=.974$ and TLI $=.952$ are above the threshold value of .95 [HuBe98]. The explained variances of the endogenous variables of information search are only moderate $\left(\mathrm{R}^{2}\right.$ for "Interaction with agent" is .21 and for "Self-controlled search" .19), but are considerably higher than those reported in former studies on information search behaviour (e.g., Punj and Stealin, 1983). 
The rather small sample size prevented a highly sophisticated operationalisation of our theoretical constructs by multiple indicators. Nevertheless, based on parameter estimates for our model we tried to assess the reliability and validity of our twoindicator measurement models (see table 1). For this purpose we used indicator reliability [Bag82], factor reliability (squared correlation between a construct and an unweighted composite of its indicators; see Bagozzi and Baumgartner, 1994) and the average variance extracted [FoLa81]. Both, factor reliability and average variance extracted can also be regarded as measures for convergent validity. Since all these values are above their corresponding threshold values [BaYi88] and as factor loadings were all significant, our construct measurements can be regarded as reliable and valid.

\begin{tabular}{|l|c|c|c|c|}
\hline Factor & Indicator & $\begin{array}{c}\text { Indicator } \\
\text { Reliability }\end{array}$ & $\begin{array}{c}\text { Factor Re- } \\
\text { liability }\end{array}$ & $\begin{array}{c}\text { Avg. Variance } \\
\text { Extracted }\end{array}$ \\
\hline Involvement & 1 & .908 & .841 & .747 \\
& 2 & .431 & & .688 \\
\hline $\begin{array}{l}\text { Product class } \\
\text { knowledge }\end{array}$ & 1 & .978 & .811 & .615 \\
\hline $\begin{array}{l}\text { Interaction } \\
\text { with agent }\end{array}$ & 1 & .848 & .761 & .761 \\
\hline $\begin{array}{l}\text { Product in- } \\
\text { spection* }\end{array}$ & 1 & $1.000^{*}$ & .864 & \\
\hline Required level & 2 & .626 & & $\geq .5$ \\
\hline
\end{tabular}

Table 1: Reliability and Validity of Measurement Models (*NOTE: error variance fixed to zero)

\subsection{Model Relationships Found}

Fit measures of the model indicate that the overall relationships hypothecated to exist for online information search sufficiently reflect reality. Interesting for the better comprehension of online information search is to what extent the hypotheses hold true and at what level of significance. Table 2 gives an overview of the findings. Figure 1 summarizes the relationships found and also includes the levels of significance reported on hereafter.

$\mathrm{H} 1$ and $\mathrm{H} 2$ postulated that the more purchase risk a consumer perceives the more will he or she search for information. In fact, H1 (users use an electronic agent 
more intensively when they perceive higher levels of risk) was not confirmed by the data. In contrast, it was observed that participants tended to rely less heavily on the interactive functionality the more risk they perceived, even though this relation is not significant. At the same time, they consulted significantly more detailed product information the more risk they perceived, confirming $\mathrm{H} 2$. This finding suggests that consumers may engage more in manually controlled forms of search the more product risk they perceive. At the same time, they do not necessarily like to rely on an agent like the one used in the experiment. This is an interesting finding, because economic theory would suggest that relying on agent advice is more rational than relying on personally sought information.

All exogenous constructs that were hypothesized to influence the perception of risk, namely product knowledge (H9), purchase involvement (H12) and the stage in the buying process (H18) proved to be in the right direction. However, none of them were statistically significant, except for product knowledge.

\begin{tabular}{|c|c|c|c|}
\hline \multirow{2}{*}{ Explanatory/ } & \multicolumn{3}{|c|}{ Endogenous variables } \\
\cline { 2 - 4 } & $\begin{array}{c}\text { Perceived } \\
\text { risk }\end{array}$ & $\begin{array}{c}\text { Interaction with } \\
\text { agent }\end{array}$ & $\begin{array}{c}\text { Self-controlled } \\
\text { search }\end{array}$ \\
\hline Perceived risk & - & $-.022(-.25)$ & $.139(1.69)$ \\
\hline Time cost of search & - & $-.161(-1.55)$ & $-.299(-3.63)$ \\
\hline Benefits of search & - & $-.190(-1.65)$ & $-.018(-.20)$ \\
\hline Product knowledge & $-.232(-2.06)$ & $-.375(-2.95)$ & $.005(.05)$ \\
\hline Involvement & $.016(.16)$ & $.315(2.54)$ & $.367(3.66)$ \\
\hline Privacy & - & $-.259(-2.77)$ & - \\
\hline Flow & - & $.152(1.57)$ & $.164(1.75)$ \\
\hline $\begin{array}{c}\text { Stage in the buying } \\
\text { process }\end{array}$ & $-.081(-.93)$ & $-.077(-.83)$ & $-.059(-.76)$ \\
\hline
\end{tabular}

Table 2: Estimation results from a model of online information search; NOTE.Standardized solution.; $t$-values are given in parentheses.

As far as the time cost of search is concerned, H4 was supported. The data revealed that the more participants had wished to do something else while shopping online, the less they manually sought for information. The same was true for agent interaction (H3), however not to a significant level. The results might indicate that 
agent functionality is relatively less impacted by consumers' time constraints than are user-driven search forms.

In contrast to $\mathrm{H} 5$, the more benefits a user derived from their interaction, the less he or she was willing to invest in the interaction process. In fact, since benefits of search were measured in the form of perceived accuracy of agent recommendation, it is intuitive to argue that the better the initial recommendation made by the agent, the less participants had an incentive to return to the interactive functionality to enhance or modify search parameters. However, even if this explanation is straightforward, the finding is still interesting because it raises awareness that one of the most basic assumptions made in information economics, which is that the more benefits one retrieves from information search, the more one searches for information, might be significantly impacted by agent technology (at least if benefits are measured in terms of identifying the right model). This impact resides in the possibility that the perceived utility of search renders decreasing marginal returns of search much quicker than this was the case for offline markets. The result is an inverse relationship between perceived search benefits and the activity of search. More research is certainly needed to investigate this finding and test its impact on the cost-benefit construct in information search theory. H6 (the more benefits a consumer perceives from interacting with an agent, the less will he or she consult detailed product information) was supported by the data, however not at a significant level.

The traditional concept of product knowledge proved to be a reliable indicator for the prediction of interaction with the agent. H7 (the more knowledge a person states to have about a product category, the less will he or she interact with an electronic sales agent) was shown to be significant at the highest level. In contrast to this finding, there was almost no effect of product knowledge on self-controlled search (H8).

Another traditional search factor, which proved highly significant for both parameters of search, agent interaction and detailed product inspection, was product involvement (H10 and H11). The more involvement a participant had with the purchase situation, the more he or she used both information sources available from the online store.

In summary, most of the traditional information search factors identified for offline markets were supported by the online model, with more than half of them at a significant level. Only two relationships did not hold true, namely the impact of perceived risk, and search benefits on the interaction process with the agent.

H13 (privacy concerns would be negatively related to consumer willingness to interact with the agent system) was corroborated by model results. In fact, the data does not only support hypothesis 13 , but also suggests that privacy concerns may have the strongest impact on agent interaction amongst all variables tested. This finding means that marketers who employ highly interactive technologies on their web sites should, in their own interests, pay attention to the privacy conditions 
they offer to their customers. However, it should also be noted here that in average more than $85 \%$ of the agent's questions were answered by the participants. This is surprising, because answering agent questions is much more informative about a user than his navigating a site. Users' privacy concerns seem to have expressed themselves more in a restriction of navigation (measurable in time and page requests) than in a reduction on information disclosed.

The flow construct for Web navigation introduced by Hoffman and Novak (1996) as well as Novak et al. (2000) proved to be significant to the model. The data confirmed that participants who perceived more flow searched significantly more manually (H15). This positive effect was, however, not significant in as far as the shopping agent was concerned (H14).

Finally, the data supported at a non-significant level that the more participants were advanced in the buying process, the less would they interact with the advisor agent (H16) or manually search for information (H17). As there were no brand names displayed in the store, the strength of this finding must, however, be regarded with caution. In case of brand display the negative effect on information search could have been stronger, with participants going directly for their consideration set.

\section{Conclusion}

The structural equation model we proposed for drivers and impediments of online information search displayed a very good level of fit and supported the majority of hypotheses made. As a result, we were able to show that determinants of information search identified in former offline studies, including product knowledge, purchase involvement and time cost seem to hold true for the online world. Furthermore, prove could be made of the influence of new variables such as privacy concerns and the achievement of a flow status.

In addition to the confirmation of these relationships, a number of interesting findings have been made that, in our view, deserve further research confirmation. These include the observation that consumers who perceive higher levels of risk prior to a purchase seem to rely less strongly on agent advice than their peers and prefer to consult the more controllable detail information available on products. Another aspect is consumers' curious handling of privacy concerns that on one side seem to be significantly addressed by decreased levels of interaction, but on the other hand also seem to be ignored when it comes to actual information disclosure.

The particular benefit of the study in the way we conducted it is that we were able to observe the 'pure' and instantaneous impact of different behavioural constructs on information search. Thus, we were able, for example, to exclude the impact of 
brands on behaviour. We also observed actual search behaviour taking place and did not have to rely on self-reported activities (as former studies did). By using the electronic shopbot, we were also able to win insights into peoples' dealings with this emerging type of technology and its relative importance in the information search process in comparison to detailed product descriptions. Here it was interesting to see that agents really represent only one way of searching for information and that, for example, in situations of higher purchase risk, they may not be the preferred tool for users to decide on their products. This finding particularly questions the 'zero-search-cost-assumptions' of online information search discussed in the introduction.

\section{References}

[Alba ${ }^{+}$97] Alba, Joseph; Lynch, John; Weitz, Barton; Janiszewski, Chris; Lutz, Richard; Sawyer, Alan; Wood, Stacy: Interactive Home Shopping: Consumer, Retailer and Manufacturer Incentives to Participate in Electronic Markets. Journal of Marketing, 61 (July), 1997, p. 38-53.

[Ann $\left.{ }^{+} 01\right]$ Annacker, Dirk; Spiekermann, Sarah; Strobel, Martin: E-privacy: Evaluating a New Search Cost in Online Environments. In: Proceedings of the $14^{\text {th }}$ Bled Conference of Electronic Commerce, Bled, Slovenia., 2001.

[Bag82] Bagozzi, Richard, P.: An Examination of the Validity of Two Models of Attitude. In: A Second Generation of Multivariate Analysis, Vol. 2, ed. Claes Fornell, New York: Praeger, 1982, p. 145-184.

[BaYi88] Bagozzi, Richard, P.; Yi Youjae,: On the Evaluation of Structural Equation Models. Journal of the Academy of Marketing Science, 16 (Spring), 1988, p. 74-94.

[BaBa94] Bagozzi, Richard, P.; Baumgartner Hans: The Evaluation of Structural Equation Models and Hypothesis Testing. In: Principles of Marketing Research, ed. Richard P. Bagozzi, Cambridge: Blackwell, 1994, p. 386-422.

[Bak97] Bakos, Yannis: Reducing Buyer Search Costs: Implications for Electronic Marketplaces. Management Science, 43 (December), 1676-1708, 1997.

[BeSm87] Beatty, Sharon E.; Smith Scott M.: External Search Efforts: An Investigation Across Several Product Categories. Journal of Consumer Research, 14 (June), 1987, p. 83-95.

[Bo189] Bollen, Kenneth, A.: Structural Equations With Latent Variables, New York: Wiley, 1989.

[Bro00] Brown, Jeffrey: Does the Internet Make Markets More Competitive? Evidence form the Life Insurance Industry, Working Paper No. RWP00-007, Harvard University Research, Boston, MA, 2000. 
[BrCu93] Browne, Michael W.; Cudeck, Robert: Alternative Ways of Assessing Model Fit. In: Testing Structural Equation Models, ed. Kenneth A. Bollen and J. Scott Long, Newbury Park: Sage, 1993, p. 136-162.

[Bru85] Brucks, Merrie: The Effects of Product Class Knowledge on Information Search Behavior. Journal of Consumer Research, 7(June), 1-16, 1985.

[CsCs95] Csikszentmihalyi, Milhay; Csikszentmihalyi, Isabella, S.: Die außergewöhnliche Erfahrung im Alltag - Die Psychologie des Flow-Erlebnisses, ed. Hans Aebli, Stuttgart, 1995.

[Cun67] Cunningham, Scott, M.: The Major Dimensions of Perceived Risk. In: Risk Taking and Information Handling in Consumer Behavior, ed. Donald F. Cox, Harvard University Press, Boston, MA, 1967, p. 265-288.

[Dei89] Deimel, K.: Grundlagen des Involvement und Anwendung im Marketing. Marketing - Zeitschrift für Forschung und Praxis, 11(8), 1989, p. 153-161.

[DoSt94] Dowling, Grahame, R.; Staelin Richard: A Model of Perceived Risk and Intended Risk-handling Activity. Journal of Consumer Research, 21(June), 1994, p. 119-134.

[Eco04] The Economist, “A Perfect Market”, May 13 $3^{\text {th }}, 2004$

[FoLa81] Fornell, Claes; Larcker, David, F.: Evaluating Structural Equation Models with Unobservable Variables and Measurement Errors. Journal of Marketing Research, 18 (February), 1981, p. 39-50.

[HäTr00] Häuble, Gerald; Trifts Valerie: Consumer Decision Making in Online Shopping Environments: The Effects of Interactive Decision Aids. Marketing Science, 19(1), 2000, p. 4-21.

[HoNo96] Hoffman, Donna; Novak, Thomas, P.: Marketing in Hypermedia ComputerMediated Environments: Conceptual Foundations. Journal of Marketing, 60(July), 1996, p. 50-64.

[HoLo99] Hoque, Abeer Y.; Lohse Gerald: An Information Search Cost Perspective for Designing Interfaces for Electronic Commerce. Journal of Marketing Research, 36(August), 1999, p. 387-394.

[HuBe98] Hu, Li-Tze; Bentler, Peter, M.: Fit Indices in Covariance Structure Modeling: Sensitivity to Underparameterized Model Misspecification. Psychological Methods, 3, 1998, p. 424-453.

[ $\left.\operatorname{Kar}^{+} 03\right]$ Karat, C.; Brodie, C.; Karat J.; Vergo, J.; Alpert, S.: Personalizing the user experience of ibm.com. IBM Systems Journal, Vol. 42, No. 4, 2003

[JaHo81] Jacoby, Jacob; Hoyer W.: Intra- and Interindividual Consistency in Information Acquisition - A Cross-Cultural Examination. In: Informationsverhalten des Konsumenten. Ergebnisse empirischer Studien, ed. H. Raffée and G. Silberer, Wiesbaden, 1981.

[JöSö96] Jöreskog, Karl, G.; Sörbom Dag: PRELIS 2: User's Reference Guide, Chicago: Scientific Software International, 1996.

[Kap $\left.{ }^{+} 74\right]$ Kaplan, Leon; Szybillo, G.; Jacoby Jacob: Components of perceived risk: A Cross-Validation. Journal of Applied Psychology, 3, 1974, p. 287-291. 
[KrWe99] Kroeber-Riel, Werner; Weinberg, Peter: Konsumentenverhalten, Vahlen: München, 1999.

[LiRu87] Little, Roderick, J., A.; Rubin, Donald, B.: Statistical Analysis with Missing Data, New York: Wiley, 1987.

[LyAr00] Lynch, John; Ariely, Dan: Wine Online: Search Costs and Competition on Price, Quality, and Distribution. Marketing Science, 19(1), 2000, p. 83-103.

[MoLe80] Moore, William, L.; Lehmann, Donald, R.: Individual Differences in Search Behavior For a Nondurable. Journal of Consumer Research, 7 (December), 1980, p. 296307.

[Moo 97] Moorthy, Shridhar; Ratchford, Brian, T.; Talukdar, Debabrata: Consumer Information Search Revisited. Journal of Consumer Research, 23(4), 1997, p. 263-277.

[MuMu98] Muthén, Linda, K.; Muthén, Bengt, O.: Mplus User's Guide, Los Angeles, CA: Muthén and Muthén, 1998.

$\left[\mathrm{Nov}^{+} 00\right]$ Novak, Thomas; Hoffman, Donna; Yung, Yiu-Fai: Measuring the Customer Experience in Online Environments: A Structural Modeling Approach. Marketing Science, 19(1), 2000, p. 22-42.

[PeTa75] Peter, Paul; Tarpey, Lawrence, X.: A Consumer Analysis of Three Consumer Decision Strategies. Journal of Consumer Research, 2 (June), 1975, p. 29-37.

[PuSt83] Punj, Girish; Staelin, Richard: A Model of Consumer Information Search Behavior for New Automobiles. Journal of Consumer Research, 9 (March), 1983, p. 366-380.

[PuSte83] Punj, Girish; Steward, Daria: An Interaction Framework of Consumer Decision Making, Journal of Consumer Research, 10 (September), 1983, p. 181-196.

[Spi $\left.{ }^{+} 01\right]$ Spiekermann, S.; Grossklags, J.; Berendt B.; Stated Privacy Preferences versus actual behaviour in EC environments: A Reality Check. Proceedings of Wirtschaftsinformatik 2001, Augsburg, September 2001.

[SrRa91] Srinivasan, Narasimhan; Ratchford, Brian, T.: An Empirical Test of a Model of External Search for Automobiles. Journal of Consumer Research, 18 (September), 1991, p. 233-242.

[SuTa98] Sundaram, D.S.; Taylor, Ronald: An Investigation of External Information Search Effort: Replication in In-home Shopping Situations. In: Advances in Consumer Research, Association for Consumer Research, 1998, p. 440-445.

[Swa ${ }^{+}$99] Swaminathan, Vanitha; Lepkowska-White, Elzbieta; Rao, Bharat P.: Browsers or Buyers in Cyberspace? An Investigations of Factors Influencing Electronic Exchange. Journal of Computer-Mediated Communication, 5 (1) 1999.

[Urb $\left.{ }^{+} 99\right]$ Urban, Glen; Sultan, Fareena; Qualls, William: Design and Evaluation of a Trust Based Advisor on the Internet. MIT Working paper.

[Vu199] Vulkan, Nir: Economic Implications of Agent Technology and E-commerce. The Economic Journal, 109 (February), 1999, p. 67-90. 
[Wei79] Weitzman, Martin: Optimal search for the best alternative. Econometrica, 47(3), 1979, p. 641-654.

[West $\left.{ }^{+} 00\right]$ West, Patricia; Ariely, Dan; Bellman, Steve; Bradlow, Eric; Huber, Joel; Johnson, Eric; Kahn, Barbara; Little, John; Schkade, David: Agents to the Rescue?. Marketing Letters, 10 (3), 2000 p. 285-300.

[Zai85] Zaichkowsky, Judith: Measuring the Involvement Construct. Journal of Consumer Research, 12 (December), 1985, p. 341-352. 